\title{
Rethinking Professional Development in Iran: Embracing Lifelong Learning
}

\author{
Zahra Rastegar Haghighi Shirazi (Corresponding author) \\ Department of English Language Teaching, Shiraz Branch, Islamic Azad University, Shiraz, Iran \\ E-mail: zrastegar@gmail.com \\ Mohammad Sadegh Bagheri \\ Department of English Language Teaching, Shiraz Branch, Islamic Azad University, Shiraz, Iran
}

Firooz Sadighi

Department of English Language Teaching, Shiraz Branch, Islamic Azad University, Shiraz, Iran

Lotfollah Yarmohammadi

Department of English Language Teaching, Shiraz Branch, Islamic Azad University, Shiraz, Iran

Received: 06-08-2013

Accepted: 06-09-2013

Published: 01-11-2013

doi:10.7575/aiac.ijalel.v.2n.6p.180

URL: http://dx.doi.org/10.7575/aiac.ijalel.v.2n.6p.180

\begin{abstract}
The central role of teachers in enhancing education quality and promoting education reform has been largely acknowledged by various researchers. However, professional development (PD) in Iran is far from satisfactory. This paper initially outlines major shifts in professional development. It then provides a critical appraisal of professional development in Iran in both pre service and in service education. Finally, it concludes by offering ways to revitalize continuing teacher professional development.
\end{abstract}

Keywords: Professional development; teachers; instructors

\section{Introduction}

The idea that teacher quality has profound consequences for students' achievement has gained unbelievable momentum in the last few decades. New educational reforms have been launched stating that in order to ensure student achievement, teacher quality should be the top priority. Teacher role and teacher professionalization have therefore assumed greater prominence. This stands in sharp contrast to the past failed attempts based on "little currency" (Darling-Hammond, 1996) for teacher professionalization.

Following a "teacher proofed" educational reform, policy makers prescribed the so- called right tests, textbooks and curriculums to guide teachers' practice (Darling-Hammond, 1996, p. 4). But this did not bring about the drastic changes in students' performance. Since then transforming teacher professional development has become a sine qua none of all educational organization improvements. Teachers are constantly pressed to upgrade and various new initiatives have been undertaken underpinned by the critical pedagogy and the constructivist approaches to teaching and learning empowering teachers to be change agents process enquiry oriented approaches to learning have replaced product transmission deficient perspectives ( Crandall, 2011). On the whole, "teacher professionalism has struck a resounding chord" (Delannoy, 2000, p. 10.) leading to the emergence of new promising approaches emphasizing process enquiry oriented approaches to learning.

\section{Major shifts in professional development}

More than ever before, novice teachers are supported by mentors in their ongoing teaching exploration being facilitated by reflection and inquiry as compared to solving problems (Chubbuck, Clift, Allard, and Quinlan, 2001 ). Not only do mentors provide new teachers with survival guides but also they do engage them in seamless procedure of professional growth.

Moreover, it has been borne out by research that in order to bring about fruitful outcomes for the whole organization, distributed leadership (Grant, 2008) based on "nurturing teacher leadership talent" ( Stewart, 2011, p. 16) is required. Through distributed leadership "the tacit and codified knowledge required to solve complex problems is dispersed throughout the organization" (Gronn, 2000, p. 333); It ensures that everyone is actively engaged in the process of school 
improvement. It necessitates coordinating with all stakeholders in a collegial atmosphere to explore the hidden potential of all members and improve this aptitude in a supportive context (Grant, 2008).

Action research, too, has gained much popularity and has been very promising in the new paradigm shift. Teachers as change agents engaging in action research continually inquire into their own practices or those of others to unravel their ambiguities, monitor their practices and bring about changes. This being done in a spiral process of plan, act, observe and reflect, takes teachers out of their 'comfort zone'( O'Connor, et al, 2006 ) and leads to their professional improvement.

However, having examined the school improvements, practitioners realized that a paramount element was still missing. "The narrow, piecemeal attempts made in the past to improve schools lacked the fundamental supportive cultures and conditions necessary for achieving significant gains in teaching and learning" (Morrissey, 2000, p. 3 ). Educational organizations, therefore, changed into learning communities for teachers, leaders and staff members recognized by shared vision, team building, collective problem solving, and collegial relationship. In this collegial atmosphere, the isolated static teachers are encouraged to individually and collaboratively engage in inquiry, reflection and dialogue (Hewitt and Little, 2005). In Donnely, et al's terms (2005, p.344) "Reflection fuels the inquiry process and shapes the foundation of professional voice".

\section{A critical appraisal of teacher professional development in Iran}

Despites the pioneering initiatives, teacher education in Iran is far from satisfactory and has not been able to keep up to its promise. Becoming a reflective practitioner is what makes a teacher ready for his professional challenges. Therefore, our aim should be to prepare professionally developed teachers who can reflect, grow and have voice in their own qualification and growth. This implies that teacher education programs should necessarily translate into professionalization for teachers ( Ejima, 2012). Taking this perspective, we will have a critical appraisal of professional development in Iranian universities among English major faculty members both at their pre-service education stage as a beginning teacher and their in-service development as a faculty member.

The initial teacher preparation in Iran still favors the traditional 'teaching practice' approach as termed by Cornu and Ewing (2008). The student teachers initially have to pass some theoretical university courses after which they engage in supervised micro teaching of skills and instructional methods in both practicum courses and real school classes as field experiences. Adopting a very narrow scope, the supervisor then evaluates the student teachers' mastery of instructional methods, and management skills irrespective of 'the larger school context' (Cornu and Ewing, 2008) and without aiming at fostering reform-minded practitioning. As Rogers and Webb (1991) explained 'All too often teacher education focuses on the 'set of skills to be learned' and ignores the development of educational and ethical decision making, thus missing the heart of the work the teachers do' (p. 176). The beginning teachers then enter their teaching profession adopting a trial and error approach not taking advantage of a comprehensive support system of induction.

As an in-service education, university instructors should participate in so many professional development workshops which cover diverse programs. But we should ask whether the outcomes gained from the professional development programs justify the costs? Unfortunately, similar to the pre-service education, in-service programs do not follow the conventions of effective professional development. Rather than synergizing various methods as demanded by various contexts, the PD programs in Iran suffering from a centralized pre-packaged tradition, adopt a single delivery method of instruction. Almost all of the PD events are held as one-size-fits- all, fragmented, incoherent, and non-continuous workshops which mostly address generic issues. Disregarding the various nature of teacher's needs, PD agendas are imposed on universities by national educational policy makers. Faculty cohorts are not involved in any participatory decision making to come up with a shared vision either.

Unfortunately, these programs usually have no serious implications and consequences for teacher and student learning because as Ahmady et al (2009) confirm they don't mirror the content and instructional strategies employed in teachers' real classrooms. Furthermore, they don't involve teachers in active experiential learning through reflection, discussion, construction of knowledge and practical examination of the material taught. Neither do they involve them in a systematic follow up such as action research or coaching to ensure transfer of knowledge. On the whole, professional development is realized as simply having teachers complete a specific number of hours of training and adding to hours of participation in workshops has replaced the real problematization of PD engagements and reflection on the achieved consequences.

Concerning the evaluation aspect, there are no mechanisms to ensure change. Rather than providing tight and systematic evaluation, a very shallow evaluation is conducted in form of simple questionnaires distributed among the participants as a post PD activity, an evaluation method which does not address the complex nature of PD interventions. And although many instructors show their discontent with the PD interventions, organizational leaders and policy makers take no problem solving approach to amend this situation.

In addition, not only don't community language learning programs exist, but also the culture of collaboration is rarely cultivated among instructors. In fact, instructors share their professional learning occasionally at break times and they do not have regular meetings for reflection and inquiry. There are no team teachings or open door policy for them to observe each other classes.

Though the formal professional development efforts have been far from satisfactory, most of the instructors are continually engaged in individual self-directed learning activities which provide an invaluable opportunity for their growth. According to Knowles (1975 cited in Ramnarayan and Hande, 2005) self-directed learning is a process in 
which the learner takes the initiatives to assess his needs, set his learning goals, takes advantages of different teaching resources, adopts a suitable learning strategy and evaluates the learning results. Being intrinsically motivated many instructors infuse a spirit of critical reflection in their teacher initiated activities. Fortunately, information explosion on internet has made it possible for instructors to orient much of their learning to authentic materials found on different educational web sites.

In addition, the national educational policy makers in Iran have recently urged the university instructors who don't hold a $\mathrm{PhD}$ degree to pursue their education. In the last couple of years, policy makers have also launched professional paper writing as a requirement for instructors' promotion. Iranians rank among great article generators (Nargesy, 2012). Since 2013 Iranian scholars including faculty members have produced 17955 ISI articles ranking $1^{\text {st }}$ in West Asia and $15^{\text {th }}$ in the world scientific production.

\section{Ways to embrace lifelong learning}

The mentioned shortcomings surely lay evidence for a pressing need to renovate teacher professional development in the Iranian context. Given the long distance between promises and realities of PD in Iran, several implications will be suggested for practitioners, leaders, policy makers and teachers.

As a first step in reinvigorating faculty development, it seems highly pertinent to abandon the behavioristic approaches to $P D$ and adopt a new concept of learning based on Vygotsky's Zone of Proximal development (ZPD) and his socio cultural theory promoting situated learning. This could be achieved through nurturing teachers' social interaction as a basis for movement towards ZPD. We should bear in mind that learners do not approach the learning task from a blank slate stance and they have their own background knowledge and experiences constructing their own world view. Therefore, they should be assisted in building on their own pre existing knowledge.

Along the same line, it seems highly pertinent to address teachers' entrenched beliefs and attitudes to come up with a new vision of reform minded teaching. Building on their pre existing background knowledge and attitude, teachers participating in education programs construct their own meaning (Vassilakis, 2004). Therefore it is vitally important to re-examine their deeply rooted opinion by raising their consciousness (Gregoire, 2003) and assisting them to reflect on and examine their own beliefs (Davis, 2006) as these prior convictions act as filters to new upcoming knowledge and information. This specially seems critical for pre service teachers entering their profession. Many of these new teachers imagine themselves standing in front of the class presenting lessons. This view is completely incompatible with conceptions of teaching, learning, and knowledge that undergird new visions of reform-minded practice (FeimanNemser, 2001)

Given the nationally imposed PD policies, analyzing teachers' driven needs should also be prioritized in PD agendas since as Knight (2002) ascertains the transferability of PD initiatives largely rests on teachers' perceived needs. Teachers will be more motivated to change their instructional methods when they see the relevance of PD issues to their own immediate teaching environments and challenges. Building on their needs analysis, much more effective PD programs can be designed which precludes the waste of budget, time and human resources and involves more teachers.

If we are to truly optimize pre-service education, the 'surveillance stance' (Smyth, 1993) should be replaced by the critical colleagueship between co-mentors in an atmosphere of collegial relationship, respect and trust for mutual sharing, growing and valuing alternative perspectives. It is important to remember that the main task of teacher educators at this stage is laying a foundation for beginning teaching and preparing novices to learn in and from their practice" (Feiman-Nemser, 2001, p. 1016). In essence, pre service education merely sets the stage for the prospective teachers. It is because of these limitations that mentoring alone doesn't help teachers thrive much and induction programs become a must. As confirmed by Serpel and Bozeman (1999) although mentoring is a paramount component of induction programs, it doesn't ensure teachers' growth by itself. This demonstrates that new teachers need to be part of a structured network in which mentors and mentees collaborate, and share their insights, experiences, and complexities of their classrooms (Johnson and Birkeland, 2003). This necessitates a different commitment both by the learners and supervisors; while the pre-service teachers should "learn to value the learning of others as much as their owns', supervisors too should learn that it is a mutual enterprise in which ' more shared learning and joint construction of what it means to teach' deems necessary (Cornu and Ewing, 2008, p. 1803).

Along the same line, although a daunting task, it seems much pertinent to relinquish the "egg crate" (Wagner, 2001) educational perspective by breaking the walls of classrooms and foster a culture of collaboration, collegiality, and trust among more experienced teachers. Bearing this in mind, instructors consider colleagues' critical reflection and their insightful criticism not as a threat rather as golden opportunities to individual, and educational organization improvement. A collegial atmosphere through professional learning provides invaluable opportunity for instructors' noble communication. This atmosphere is fostered by "personal conversations, frequent dialogue, shared work, and shared responsibilities. As individuals interact with one another, they tend to listen across boundaries-boundaries erected by disciplines, grade levels, expertise, authority, position, race, and gender." (Lambert, 1998, p. 79). Similarly, involving instructors in all stages of PD efforts including planning, execution (Darling-Hammond \& Sykes, 1999) and evaluation as a form of distributed leadership nurtures teachers' enthusiasm and improves their professional capability.

If PD innovations are to truly flourish, they should be executed in their entirety. Training is just the beginning of renewal trip. It doesn't, however, secure the transfer of the learnt material. So, it is suggested that PD policy makers and organizers encourage teachers to apply the learnt material and provide them with ongoing follow up, support and assistance. They can ask instructors to reflect on the achieved results and to make informed decisions in accordance with their reflective practice. 
Furthermore, due to their down-falls, the traditional workshops addressing generic issues should give way to reformbased PD initiatives aimed at building capacity and promoting a culture of lifelong learning. More specifically, the top down, short period nature of professional development should give way to bottom up, continuous and in situ learning focusing on teacher and student learning. The sporadic fragmented workshops as the sole mode of elevating teaching profession not only produce no far reaching consequences but also diminish the universities' ability to meet its other financial obligations. The reform-based instruction changes take extended time and effort. It is high time to abandon the theory practice divide and try to gain information underpinned by simultaneous application of both theory and practice. The fragmented incoherent nature of PD programs could well be tackled using a conceptual framework which includes its perspective towards learning, the role of teacher, pedagogy and the mission of the organization. It is only through considering a conceptual framework that the foundations for curriculum development, pedagogy and assessment procedures would be laid.

Organizational supporters play a key role in helping teachers embrace lifelong learning by providing them with more resources and opportunities such as handouts, self-assessment checklists, and discussion meetings, online forums and encouraging implementation through collaborative endeavors. As a post intervention step, for instance on site cocoaches can be accessible to teachers to provide them with feedback and help. Allocating incentives such as salary promotion and tenure gaining can also encourage their professional development. Also needed are new systematic methods to ensure effective PD. It would seem that benchmarks, standards and assessment criteria to evaluate faculty members' performance would ensure quality implementation. Generally, follow up organizational support prevents teachers from "reverting back into their old practices" (Beeby, 1980, p. 466).

It is worth mentioning that the PD efforts should not only consider taking into account the teachers' immediate feedback, but also teacher learning, teacher transfer of the learnt knowledge and its contribution in fostering student achievement and its alignment with the missions, goals and priorities of university (Guskey, 1999). In order to systematically tap into teachers' improvement, we could ask them to present their portfolio recording their progress. Guskey (1999) has rightly warned us not to restrict our systematic evaluation to formal professional development interventions, rather he states that all ongoing individually and collaboratively guided activities should be 'goal-driven' and their alignment with these pre-established goals should be explored. The departmental structure should also motivate collaborative cooperation among various specialists.

It is a fact that time pressure precludes teachers from involving in face to face interaction. Fortunately, technology has mitigated this constraint. Nowadays, digital scaffolders provide teachers with unique opportunity to articulate their thoughts, and engage in collaborative problem solving and reflection (Ross, 2011). These wonderful tools address teachers' diverse needs and make a great compendium of expert ideas available to them. Teachers can form virtual professional learning communities; They can also subscribe to individual personal networks such as webinars, podcasts, online videos, vodcasts, web conferencing, etc. They may also problematize their teaching experiences through eportfolios (Beach, 2012). Clinging to old beliefs and resisting change precludes teachers from the pursuit of their excellence. Therefore, modernization of teacher professional development to embark on new changes in our teacher education system should be considered.

Finally, despite standing high in paper writing, there is still room for Iranian faculty members to do action research. Through action research, instructors should draw on their research-based theories and then apply that knowledge into their practice.

\section{Conclusion}

Taken all together, a radical overhaul of education system of teaching as telling and learning as listening to provide a drastic change in provision for pre-service education, induction and professional development of instructors is required. However, we should bear in mind the fact that "each phase in a continuum of teacher learning has a unique agenda shaped by the requirements of good teaching and where teachers are in their professional development" (FeimanNemser, 2001, p. 1014). If we teachers are to truly stay current through professional development, we should take a path rarely taken before in the Iranian context. This necessitates stepping into lifelong learning road oriented toward reflection, collaboration, and true information sharing with the aim of improving self and others.

It is hoped that the pedagogical implications of this critical review would inform practitioners and policy makers to engineer the PD programs fueled by collaborative inquiry to facilitate achieving much more satisfactory results for teachers and learners.

\section{References}

Ahmady, S., Changiz, T., Brommels, M., Gaffney, A. F., \& Masiello, I. (2009). The Status of Faculty Development Programmes in Iran after the Medical Education Reform: A Systematic and Comprehensive Approach. International Journal for Academic Development, 14 (2), 99-110.

Beach, R. (2012). Can online learning communities foster professional development? Richard Beach Language Arts, 89 (4), 256-262.

Beeby, C. E. (1980). The thesis of the stages fourteen years later. International Review of Education, 26 (4), 451-474.

Cornu L. R., Ewing R. (2008). Reconceptualizing professional experiences in pre-service teacher, education reconstructing the past to embrace the future, Teaching and Teacher Education, 24, 1799-1812. 
Crandall , J. (2011). Teaching as Lifelong Learning: Reflections on Professional Development. Journal of English studies, 6, 1-20.

Chubbuck, S. M., Clift, R. T., Allard, J. \& Quinlan, J. (2001). Playing it safe as a novice teacher, implications for programs for new teachers. Journal of Teacher Education, 52 (2), 365-376.

Darling-Hammond, L. and Sykes, G. (1999). Teaching as the Learning Profession : Handbook of Policy and practice. San Francisco: Jossey- Bass.

Davis, E. A. (2006). Characterizing productive reflection among pre-service elementary teachers: Seeing what matters. Teaching and Teacher Education, 22, 281-301.

Delannoy, F. (2000). Teacher training or lifelong professional development? World wide trends and challenges, TechKnowLogia, 10-13.

Donnely, A. D., Morgan, D. N., Deford, D. E., Files, J., Long, S., Mills, H., Stephenes, D., Styslinger, M. (2005). Transformative professional development: Negotiating Knowledge with an inquiry stance, Language Arts, 82 (5), 336346.

Ejima, O. S. (2012). Teacher professional development in the $21^{\text {st }}$ Nigeria. Global voice of educators, 1 (1), 1-6.

Feiman-Nemser, Sh. (2001). From Preparation to teaching: Designing continuum to strengthen and sustain teaching. Teacher College Record, 103 (6), 1013-1055.

Grant, C. (2008). 'We didn't put our pieces together': exploring a professional development initiative through a distributed leadership lens. Journal of Education, 44, 85-107.

Gregoire, M. (2003). Is it a challenge or a threat? A dual process model of teacher's cognition and appraisal processes during conceptual change. Educational Psychology Review, 15, 147-179.

Gronn, P. (2000). Distributed properties: A new architecture for leadership. Educational Management and Administration, 28 (3), 317-338.

Gunter, H. M. (2005). Leading teachers. London: Continuum.

Guskey, T. R. (1999). Evaluating professional development. Thousand Oaks, CA: Corwin Press.

Hewitt, R. \& Little, M. (2005). Leading Action Research in Schools. Florida State of Florida.

Johnson, S. and Birkeland, S. (2003). Pursuing a sense of success: New teachers explain their career decision. American Education. Research Journal, 40 (3), 581-617.

Knight, P. (2002). A systemic approach to professional development: Learning as practice. Teaching and Teacher Education, 18, 229-241.

Lambert, L. (1998). Building leadership capacity in schools. Alexandria, VA: Association for supervision and curriculum development.

Morrissey, M.S. (2000). Professional learning communities: An ongoing exploration.

Nargesy, H. (2012). The evaluation of a teacher training system: A study on the efficacy of teaching training policy in the last three decades in the field of English Teaching in Iran. Life Science Journal, 9 (4),660-663.

O’Connor, K. A., Greene, H. C., \& Anderson, P. J. (2006). “Action research: A tool for improving

teacher quality and classroom practice". Paper presented at the American Educational Research Association (AERA), San Francisco, CA.

Ramnarayan, K.\& Hande, Sh. (2005). Thoughts on self-directed learning in medical schools: Making students more responsible. New Horizons for Learning Online Journal [Online] Available. http://www.newhorizons.org/lifelong/higher_ed/ramnarayan\%20hande.htm (June, 2013)

Rogers, W., \& Webb, J. (1991). The ethic of caring in teacher education. Journal of Teacher Education, 42 (3), 173181.

Ross, J. D. (2011). Online professional development: Design, deliver, succeed! Los Angeles: Corwin Press.

Serpell, Z. and Bozeman, L. (1999). Beginning teacher induction: A report of beginning teacher effectiveness and retention. Washington, Dc: National partnership for excellence and accountability in teaching.

Smyth, J. (1993). Reflective practice in teacher education and other professions. Learning in the field: The current face of practical experience in professional preparation. In Post conference publication of the 5th national practicum conference, Sydney.

Stewart V. (2011). Raising Teacher Quality Around the World, The effective Educator, 68 (4), 16-20.

Vassilakis, G. (2004). Teacher education: What does it mean. ELT News, [Online] Available: http://www.scribd.com/doc/23295881/Teacher-Education-What-Does-It-Mean (June, 2013)

Wagner, T. (2001). Leadership for learning: An action theory of school change. Phi Delta Kappan, 82, (5), 378-383. 